\title{
Association between serum 25(OH)D and the risk of cognitive decline in the very old: The Newcastle 85+ study
}

\author{
A. Granic ${ }^{1}$, T. Hill ${ }^{2}$, T. Kirkwood ${ }^{1}$, K. Davies ${ }^{1}$, J. Collerton ${ }^{1}$, J. C. Mathers ${ }^{1,2}$ and C. Jagger ${ }^{1}$ \\ ${ }^{1}$ Institute for Ageing and Health, Newcastle University, Newcastle NE4 5PL, UK and ${ }^{2}$ Human Nutrition Research Centre, \\ Campus for Ageing and Vitality, Newcastle University, Newcastle NE4 5PL, UK
}

The world's population is ageing and the $85+$ age group is the fastest growing section. Nevertheless little is known about their health trajectories and, in particular, the role of nutrition in maintenance of cognitive function ${ }^{(1)}$. Recent epidemiological and molecular data points to the role of serum 25-hydroxyvitamin $\mathrm{D}(25(\mathrm{OH}) \mathrm{D})$ in brain health and cognitive decline ${ }^{(2)}$. We tested the hypothesis that nonoptimal concentrations of serum $25(\mathrm{OH}) \mathrm{D}$ (both low and high) are associated with increased risk of global and attention-specific cognitive decline over 3 years.

Cross-sectional (baseline) and prospective (1.5 and 3-year follow-up) analyses of 845 participants from the Newcastle $85+$ study ${ }^{(3)}$ were assessed for global (measured by the Standardized Mini-Mental State Examination [SMMSE] ${ }^{(4)}$ ) and attention-specific (measured by Attention Battery of Cognitive Drug Research [CDR] computerized system ${ }^{(5)}$ ) cognitive tasks in relation to serum $25(\mathrm{OH}) \mathrm{D}$ quartiles ( $\leq 25 \mathrm{nmol} / 1$ [lowest]; $26-39 \mathrm{nmol}$ and $40-62 \mathrm{nmol}$ [middle two]; and $\geq 63 \mathrm{nmol} / 1$ [highest]). 25(OH)D was measured by radioimmune assay from fasting blood samples. Prevalence of cognitive impairment was defined as scoring below 26 points of SMMSE at baseline and incidence as crossing the 25 points cut-off at follow-up, respectively. Changes in attention tasks over 3 years (Simple Reaction Time [SRT], Choice Reaction Time [CRT], Digit Vigilance [DVT], Power of Attention [PoA], and Cognitive Reaction Time [CogRT]) were examined by multilevel linear modeling with multivariate adjustments for putative risk factors for cognitive decline/dementia and variables associated with baseline $25(\mathrm{OH}) \mathrm{D}$ concentration.

After adjusting for potential confounders (sex, season of blood testing, education, income, smoking, alcohol consumption, waist-hip ratio, chronic diseases and renal impairment), the prevalence of impaired global cognitive functioning was significantly increased for both the lowest quartile $(\mathrm{OR}=1.63,95 \% \mathrm{CI}: 1.07-2.48, P=0.02)$ and the highest $(\mathrm{OR}=1.74,95 \% \mathrm{CI}: 1.15-2.63, P=0.009)$ compared with the middle quartiles. Excluding participants who were taking vitamin D containing supplements or medication from the analysis revealed an increased risk of prevalent cognitive impairment only in the lowest quartile (OR $=1.79,95 \% \mathrm{CI}: 1.15-2.77, P=0.009)$. The incidence of impaired global cognitive functioning $(\mathrm{OR}=1.40,95 \% \mathrm{CI}: 0.78-2.51, P=0.27$ for lowest, and $\mathrm{OR}=0.96,95 \% \mathrm{CI}: 0.53-1.72, P=0.88$ for highest quartile) or global cognitive decline (data not shown) was not related to baseline $25(\mathrm{OH}) \mathrm{D}$ concentration. However for participants in the highest $25(\mathrm{OH}) \mathrm{D}$ quartile DVT attention declined by $11.7 \mathrm{~ms}(\mathrm{SE}=5.8 \mathrm{~ms}, P=0.05)$ more per month over the study period compared with those in middle quartiles after adjusting for potential confounders.

Non-optimal (low or high) serum $25(\mathrm{OH}) \mathrm{D}$ concentrations are strongly associated with prevalent cognitive impairment in the very old, but do not appear to be associated with global cognitive decline or incident cognitive impairment although this may be due to possible learning effects with the SMMSE. In addition, high serum $25(\mathrm{OH}) \mathrm{D}$ was associated with worse performance in more objectively measured attention-specific tasks over 3 years. Further investigation is warranted to determine whether $25(\mathrm{OH}) \mathrm{D}$ affects other domain-specific cognitive functions in this age group.

1. Bowman GL, Silbert LC, Howieson D et al. (2012) Neurology 78, 241-249.

2. Buell JS, \& Dawson-Hughes B (2008) Mol Aspects Med 29, 415-422.

3. Collerton J, Barrass K, Bond J et al. (2007) BMC Geriatr 7, 14.

4. Folstein MF, Folstein SE, \& McHugh PR (1975) J Psychiartic Res 12, 189-198.

5. Simpson P, Surmon D, Wesnes K et al. (1991) Int J Geriatr Psychiatry 6, 95-102. 